\title{
Economically Optimal Sizing and Operation Strategy for Solid Oxide Fuel Cells to Effectively Manage Long Term Degradation
}

Mina Naeini ${ }^{1}$, James S. Cotton ${ }^{2}$, Thomas A. Adams II ${ }^{1 *}$

${ }^{1}$ Department of Chemical Engineering, McMaster University

2Department of Mechanical Engineering, McMaster University

McMaster University, Hamilton, ON, L8S 4L7, Canada; naeinim@mcmaster.ca; cottonjs@mcmaster.ca * Corresponding author: tadams@mcmaster.ca

Fig. S1 illustrates power output profile for 1-, 2-, 5-, and 10-year SOFCs over the plant lifetime in base case. As it was mentioned, no matter the replacement schedule, the average power output over the cells lifetime is $550 \mathrm{MW}$ (AC). Power output reduces over time before SOFCs are replaced with identical cells. 


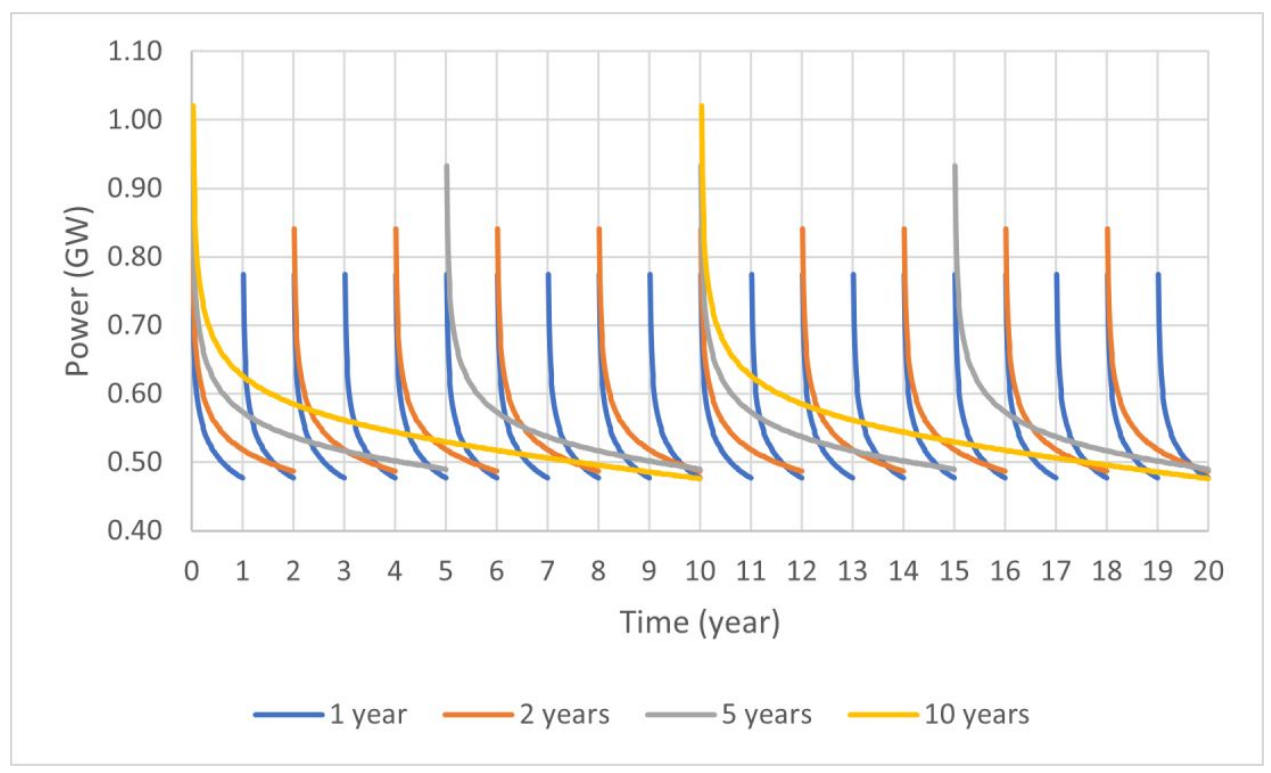

Fig. S1. Power output profile for 1-, 2-, 5-, and 10-year SOFCs over the plant lifetime.

Fuel flow rate and efficiency profiles for 1-, 2-, 5-, and 10-year SOFCs over the plant lifetime are shown in Figs. S2 and S3, respectively. Fuel flow rate, similar to current density and power, decreases over cells lifespan, while efficiency increases. Additionally, SOFCs that operate for a longer period of time, with lower current densities and higher voltages, feature higher efficiencies. 


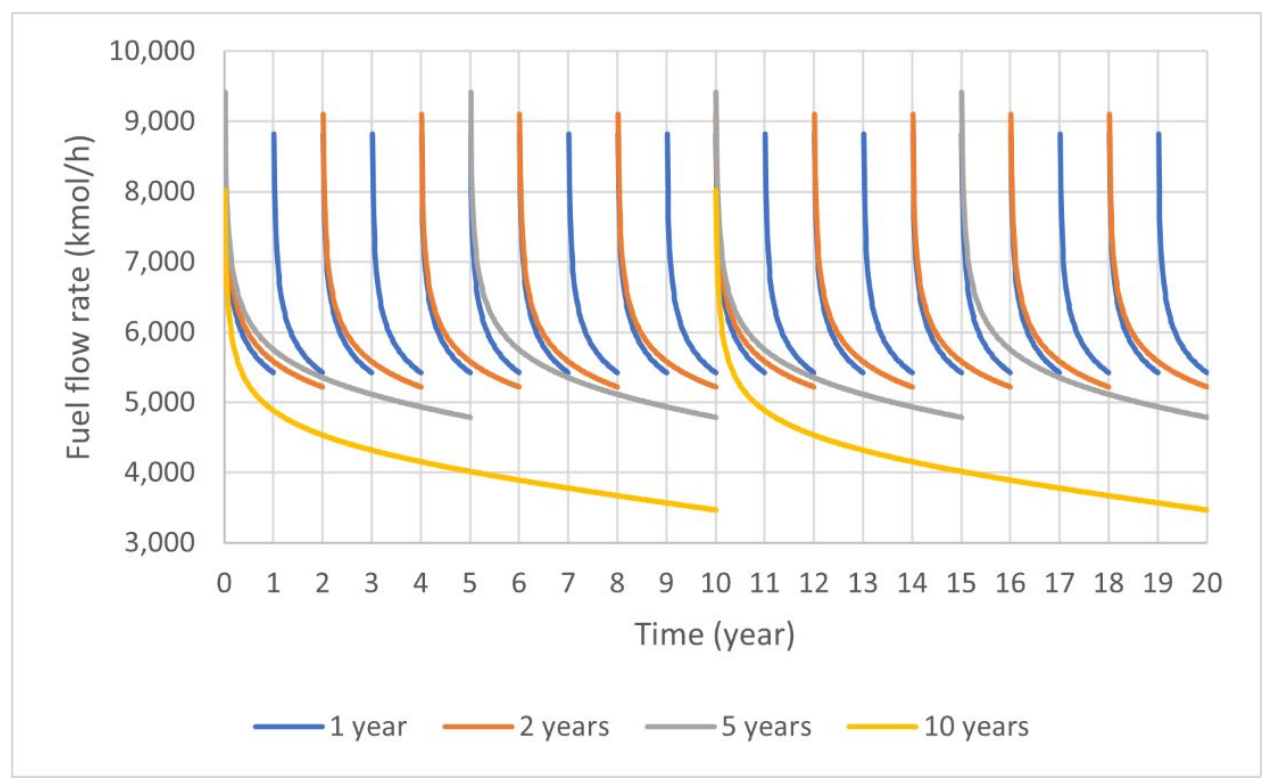

Fig. S2. Fuel flow rate profile for 1-, 2-, 5-, and 10-year SOFCs over the plant lifetime.

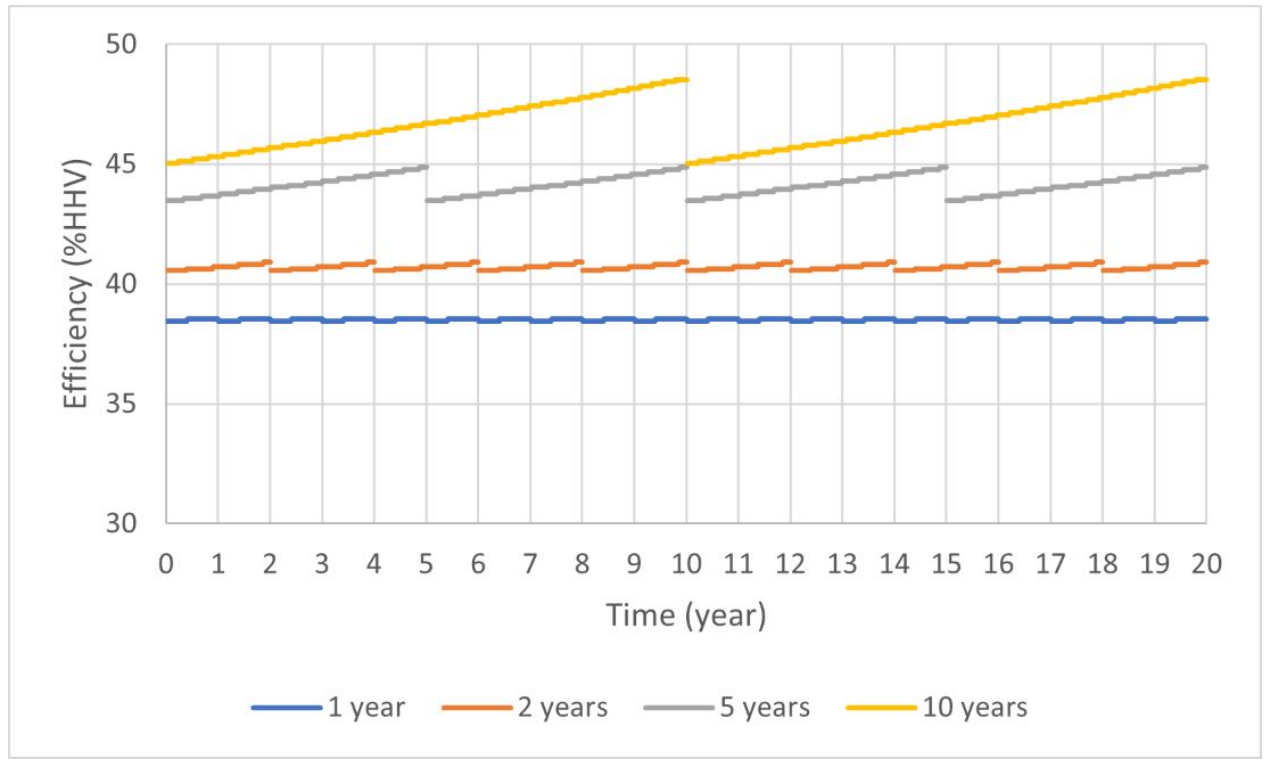

Fig. S3. Efficiency profile for 1-, 2-, 5-, and 10-year SOFCs over the plant lifetime. 